\section{A National Health Service}

The most basic function of government is the provision of law and order (including defence), thereby preserving the essential features of a national civilization - as Général de Gaulle is said to have remarked, individual freedom of thought, of belief, opinion, of work and of leisure is the root of civilization. It is not immediately obvious why the provision of health services should be part of the duty of the state, rather than an individual duty. To be sure, healthcare is often listed as a state duty-along with education; scientific research, development and innovation; and the alleviation of indigence. Indeed, around the middle of the 20th century in the UK we had the Beveridge report, which proposed a way of abolishing what were perceived as five giant evils - want, disease, ignorance, squalor and idleness [1]. It might well be presumed that ill health, ignorance and want make the individual freedoms mentioned by de Gaulle nugatory, the abolition of the evils being seen as an essential part of the progress of society. Acceptance of the Beveridge report's recommendations marked the beginning of the "welfare state", enacted with such instruments as the Education Act (1944) and the National Health Service Act (1946). State interference in scientific research had begun earlier; e.g., with the establishment of the Department of Scientific and Industrial Research in 1923, following the lead of major continental European powers such as Germany, which had established the Kaiser Wilhelm Gesellschaft in 1911 as an instrument for science to serve the state, with a clear economic motivation.

The following ideas may have contributed to the great extension of state activity in national life indicated by the Beveridge report:

(1) The enormous forces of production unleashed by the development of machinery. As Spengler had written a decade earlier, "die Zivilisation ist selbst eine Maschine geworden" [2]. A well-organized industrial and agroindustrial nation such as the USA had achieved such an excess of production over the requirements of its population to be almost embarrassing, and disposing of the excess was becoming increasingly problematical [3]. In the midst of such abundance, albeit less in the UK than in the USA, it was certainly embarrassing to note the persistent presence of the five evils identified by Beveridge.

(2) The USSR had demonstrated that central state planning and control could achieve astonishingly rapid progress in industrialization and agroindustrialization.
Many observers considered it to be far more rational than relying on the fragmented individual self-interest expounded by Adam Smith [4].

At the same time the field of cybernetics was still in its infancy and ideas about the power of self-organization were inchoate. If anything, such notions about cybernetics as were at that time emerging tended to reinforce the view that central control was more efficient (as judged by the amount of effort required to achieve a certain end) than seemingly uncoördinated individual efforts, even with the partial coöperation embodied in the capitalist firm.

In retrospect, there was an air of unseemly haste about the ushering in of the welfare state. If indigence were to be eliminated through "social security", would not the rest follow? - de facto everyone would henceforth be able to afford medical treatment and education, the latter itself contributing to the acquisition of knowledge of how better to look after one's health. Indisputably, good health lies at the core of the existence of any living creature. It follows that it is an important part of being human, and it is only natural for a human being to devote considerable effort to maintaining good healthimplying the need for both knowledge and money. But not everyone can be a medical student, and not everyone has essentially unlimited financial resources, hence trade-offs are necessary and the effectiveness of these trade-offs might be increased by coöperation. ${ }^{1}$ In effect, the National Health Service Act forced the entire nation to coöperate in matters of health. It was, in fact a giant experiment. Two of its cardinal principles were that (i) a person ought not to be financially deterred from seeking medical assistance at the earliest possible stage; and (ii) standards of health provision should be uniform throughout the nation [6].

The first principle makes sound economic sense. A healthy worker is a more productive worker than an unhealthy one, and since a late diagnosis almost invariably leads to more trouble and expense to cure a malady than an early one, the removal of any obstacles to seeking medical treatment (since the earlier a malady can be diagnosed, generally the better the chances of survival) should diminish the overall cost of keeping the nation in health. The second principle accords with ideas of national solidarity - for the same reason it would be repugnant if the postage from London to Carlisle cost more than that from London to Brighton, even though the actual cost of the former service must considerably exceed that of the latter.

\footnotetext{
${ }^{1}$ Fascinatingly, Adam Smith had written a book about the benefits of coöperation about 15 years before the Wealth of Nations was published [5].
} 
At the time of its introduction, the main argument against the National Health Service (NHS) was that the principle of universal healthcare provided free at the point of use would be abused - that it would transform the nation into one of citizens who gave what they must to the state and took what they could [6]. In 1952, just six years after the launch of the NHS in 1948, another NHS bill was being debated in Parliament. The NHS was by then in acute financial difficulty and it was proposed to introduce some charges - for example, $1 \mathrm{~s}$. for prescriptions and $£ 1$ for routine dental treatment. Some of the envisaged abuses had, in fact, been found to occur: there was a tendency for the overliberal prescription of drugs (contributing to the longer term problem of antimicrobial antibiotic resistance, with which we are confronted today). The principle that "a person ought not to be financially deterred from seeking medical assistance at the earliest possible stage" was found not to be as straightforwardly defensible as had once been thought. Many minor ailments would cure themselves without any medical intervention; the premature administration of drugs, through deleterious side-effects, caused more harm than good. ${ }^{2}$ On the supply side, pharmaceutical companies were aggressively advertising proprietary drugs, and it had been found to be necessary to place some restrictions on such advertising. The 1952 House of Commons debate got bogged down in minutiae, such as the question whether the proposed charge for surgical boots was justified, on the grounds that the wearer would otherwise have had to pay for ordinary boots [7]. Conclusions were hampered by the lack of any framework with which the benefits and disbenefits could be quantitatively assessed at the national level.

The reason for the introduction of the 1952 NHS bill was that the government of the day had become alarmed at the ballooning cost of the NHS, but had no way of judging how much was reasonable to pay. In order to enable a quantitative discussion, a numerical measure of health is needed. One that is widely used, albeit rather crude, is life expectancy, whence the life quality index $Q$, introduced at various times by Nathwani [8], Pandey [9] and Thomas [10], and in its basic form self-evident:

$$
Q \sim G X
$$

where $G$ is income in currency units and $X$ is life expectancy in time units. In developing this idea, $G$ or $X$ or both are raised by an exponent. Different authors have proposed different exponents. For example, Pandey et al. have proposed $c /(1-c)$ for $G$ [9], where $c$ is the fraction of time spent working to generate the income (although this leads to the rather paradoxical result that the contribution of income to $Q$ increases with a decrease of leisure time; a first-principles approach suggests an exponent of $1 / c$; Pandey et al. derive their result from a consideration of the somewhat dubious Cobb-Douglas formulation of a production function), and Thomas has proposed $1-\varepsilon$, where $\varepsilon$ is the risk-aversion associated with measures that will extend life expectancy [11]. This notion is derived from the utility of money $[12,13]$, a concept formulated by D. Bernoulli [14], based on the observation that a person is likely to value initial increments of income more than later ones (roughly, utility $\sim \log G$ ).

By applying perturbation theory to the developed form of (1), we can obtain an equation for the greatest sensible amount, $\delta G$, to spend on healthcare, prolonging life by $\delta X$, that just falls short of causing a decline in $Q$. The result of this procedure is a line (a Pareto front) on a plot of $G$ versus $X$ - there may be no unique solution.

One unfortunate feature of raising the variables on the right-hand side of equation (1) to some power is that $Q$ acquires a dimensionally awkward, and variable, unit. Nevertheless, this does not matter if the output of the calculation is not $Q$ but that value of $\delta G$ that optimizes $Q$. Thomas has defined the "J-value" or simply $J$ as the ratio of the actual spend $\delta \hat{G}$ to this maximum sensible spend according to the life quality consideration [11]: ${ }^{3}$

$$
J=\delta \hat{G} / \delta G=\delta \hat{G} X(1-\varepsilon) /(\delta X G) .
$$

It would appear to be perfectly rational for an individual to use this approach to determine whether to spend money on a personal healthcare measure. Knowing what value of risk-aversion to use might be a problem [13]; a value of 0.95 has been inferred from global $(G, X)$ data [11]. A more severe problem is that life expectancy might be perceived as a somewhat inadequate measure of good health. Those features of mental and physical (if we are permitted to make a distinction) health that contribute to the vivacity of physical and mental activity are not so readily captured by measurable parameters (doubtless "happiness", conventionally considered to be unmeasurable, is an ingredient), which is perhaps why remedies and health enhancements are so eagerly, and often vainly, sought.

The J-value was originally conceived as a rational means of evaluating proposed safety measures, such as train protection and warning systems, systems for eliminating radioactive leakage in the nuclear power industry, and chemical pollution, as well is life-prolonging drugs and measures to contain bovine spongiform

\footnotetext{
2 A further bill, Therapeutic Substances (Prevention of Misuse), was introduced in 1953.

3 See the Appendix for the derivation of this equation.
} 
encephalopathy (BSE) [15]. Train protection and warning systems date back at least to the Great Western Railway's "Automatic Train Control" introduced, at considerable expense, in $1906 ;{ }^{4}$ Thomas et al. have shown that the TPWS installed in the early years of the present century has a J-value that considerably exceeds unity [15], in other words provides a clear disbenefit. As for BSE, whereas the pre-1996 countermeasures had J-values below unity, the post-1996 countermeasures' J-values exceeded 100 , representing a colossal waste of public resources.

For such measures, affecting large numbers of people, it seems entirely appropriate to use (possibly discounted) average life expectancy $G$ as the measure of health, and average income (GDP per capita - which of course then includes "social income"-public services paid for using taxation revenues) for $X$; the resulting $\delta X$, the maximum sensible cost of the "safety spend" (lifeprolonging measure) per capita, is then multiplied by $N$, the population, in order to be compared with the actual cost of the safety spend.

Hitherto the J-value has been applied to welldefined safety measures, which not only have a cost that is readily ascertainable, but which also have a clearly apparent effect on life expectancy (such as a drug, or the removal of exposure to radiation). The difficulty in applying equation (2) to the entire NHS is knowing what overall effect the NHS has on prolonging life. One way forward would be to average $\delta X$ for each patient (this assumes that were the NHS unavailable, no other treatment would be accessible). Initially a representative statistical sample of patients could be taken to provide an estimate.

There remains the question whether less could be spent to achieve the same average $\delta X$. Since the NHS was founded there has certainly been an enormous accumulation of staff other than frontline medical workers, which is of course very expensive. This evolution is perhaps an inevitable consequence of Parkinson's law. Hope is now being placed on the deployment of new advanced technologies, such as "smart" sensors for self-healthcare [16] and labs-on-chips for rapid diagnosis [17], which should lead to cost reductions, although no serious attempts to estimate how much they might be have been undertaken. Interestingly, during the past few decades the increasing deployment of expensive equipment such as $\mathrm{CT}$ scanners is often said to have been responsible for the seemingly inexorable trend of increasing costs, but this inference seems to exclude the presumably better patient outcomes as a result of the deployment, hence prolongation of life, taking which into account might well reveal that the J-value is diminishing (the calculation does not yet appear to have been attempted).

A little over a century ago, Kropotkin pointed out that medical intervention was often pointless among the lowest ranks of society: they were in poor health because of lack of sound nutrition and poor lifestyle (e.g., insufficient leisure time) [18]: the priority surely was to alleviate these wants rather than facilitate access to medicine. Today, the poverty about which Kropotkin so eloquently writes has been largely eliminated. Paradoxically there is now a great increase in diseases due to excessive food intake and lifestyles that are too sedentary, as well as mental health problems. This dramatic change has taken place under the aegis of the NHS, almost pari passu with the increase in the NHS budget.

Why is that? Early hopes that the NHS would be so effective in increasing the general health of the population that it would become largely superfluous except for treating the victims of accidents have not materialized. Not only has the overall cost continuously increased, but the proportion of resources devoted to chronic disease has also increased. Puzzlingly, these increases have occurred pari passu with increased expenditure on education [19], so whatever is being taught does not seem to have much relevance to looking after oneself. Is it a manifestation of Jevons' paradoxor, what amounts to the same thing, moral hazard? It was an early criticism of the NHS that it was not designed to be concerned with preventive medicine; indeed a more appropriate name might have been the National Disease Service (NDS). Nowadays the government, whose feeling that it is responsible for the nation's health has become more and more entrenched, is using a variety of "sticks" (mainly taxation, on alcohol, tobacco, automotive fuel, sugar etc.) and "carrots" (e.g., the Behavioural Insights Team, which "uses insights from behavioural science to encourage people to make better choices for themselves and society"5) to promote what it believes is conducive to good health. Clearly the market has, appallingly, failed to do that. Or is health simply one of many ingredients in a complex set of trade-offs, which equation (1) is too simple to capture?

\section{J.J. RAMSDEN}

\footnotetext{
${ }^{4}$ Perusal of the minutes of board meetings of the company, if they are still available, might yield the extent to which cost-benefit considerations entered into the decision to proceed with the ATC system. A common difficulty, obviated by the J-value approach, is that life is considered to be priceless, whence any measure that achieves a reduction in fatalities, no matter how minor, should be adopted.

5 From the website www. behaviouralinsights.co.uk (accessed 30 June 2018).
} 


\section{References}

1. W. Beveridge, Social Insurance and Allied Services. London: HMSO (1942).

2. O. Spengler, Der Mensch und die Technik. Munich: C.H. Beck(1931).

3. G. Piel, For the living generation. In: The Science of Science (eds M. Goldsmith and A. Mackay), pp. 56-70. London: Souvenir Press (1964).

4. A. Smith, The Nature and Causes of the Wealth of Nations. London: William Strahan (1776)

5. A. Smith, The Theory of Moral Sentiments. London: Andrew Millar (1759).

6. National Health Service Bill (debate on 2nd Reading). HC Deb 30 April 1946 vol. 422 cc43-142.

7. National Health Service Bill (debate on 2nd Reading). HC Deb 27 March 1952 vol. 498 cc841-896; 961-1029.

8. J.S. Nathwani, N.C. Lind and M.D. Pandey, Energy Decisions for Life Quality. Springer (2009).

9. M.D. Pandey, J.S. Nathwani and N.C. Lind, The derivation and calibration of the life-quality index (LQ I) from economic principles. Structural Safety 28 (2006) 341-360.

10. P.J. Thomas, D.W. Stupples and M.A. Alghaffar, The extent of regulatory consensus on health and safety expenditure. Part 1. Development of the J-value technique and evaluation of the regulators' recommendations. Trans. IChemE B 84 (2006) 329-336

11. P. Thomas, Does health spending need to outpace GDP per head? Nanotechnol. Perceptions 13 (2017) 17-30.

12. P.J. Thomas, An absolute scale for measuring the utility of money. J. Phys. Conf. Ser. 238 (2010) 012039.

13. P.J. Thomas, Measuring risk-version: The challenge. Measurement 79 (2016) 285-301.

14. D. Bernoulli, Specimen theoriae novae de mensura sortis.
Commentarii Academiae Scientiarum Imperialis Petropolitanae 5 (1730) 175-192.

15. P.J. Thomas, D.W. Stupples and M.A. Alghaffar, The extent of regulatory consensus on health and safety expenditure. Part 2. Applying the J-value technique to case studies across industries. Trans. IChemE B 84 (2006) 337-343.

16. R. Sullivan and I. Rafi, The role of self-care and the use of smart sensors in the UK's health provision. Nanotechnol. Perceptions 13 (2017) 5-16.

17. G.C. Holt, The take-up of near-patient testing (lab-on-achip). Nanotechnol. Perceptions 13 (2017) 45-54

18. P. Kropotkin, Aux jeunes gens. Les Temps Nouveaux $\mathrm{N}^{\circ} 31$ (1904).

19. J.J. Ramsden, The future of healthcare. J. Biol. Phys. Chem. 14 (2014) 31-33.

\section{Appendix}

We write equation (1) as

$$
Q=G^{1-\varepsilon} X .
$$

Applying a small perturbation,

$$
\delta Q=-(\partial Q / \partial G) \delta G+-(\partial Q / \partial X) \delta X
$$

which yields

$$
\delta Q=-(1-\varepsilon) G^{-\varepsilon} X \delta G+G^{1-\varepsilon} \delta X
$$

We divide by (3) to get

$$
\delta Q / Q=-(1-\varepsilon) \delta G / G+\delta X / X,
$$

from which it follows that the maximum sensible expenditure $\delta G$ is given by putting $\delta Q=0(Q \neq 0)$ in (6) and finding the solution of the resulting

$$
(1-\varepsilon) \delta G / G=\delta X / X \text {. }
$$

